\title{
Conducting Mathematical Research with Undergraduates
}

\author{
Gareth E. Roberts*
}

November 26, 2008

\begin{abstract}
The notion that undergraduates are capable of making profound and original contributions to mathematical research is rapidly gaining acceptance. Undergraduates bring their enthusiasm, creativity, curiosity and perseverance to bona fide research problems. This article discusses some of the key issues concerning undergraduate mathematical research: selecting good research students, finding appropriate research questions, mentoring versus collaboration, and presenting and publishing student work. Some useful professional and financial resources supporting undergraduate research are also highlighted.
\end{abstract}

Key Words: Undergraduate research, mentoring undergraduates

\section{Introduction}

Several years ago, while at a research conference in Europe, I described to some colleagues an interesting problem in dynamical systems I was studying with an undergraduate student of mine. The reactions I received went something like, "That's nice but don't expect to get far working with an undergraduate," and "Undergraduates are good at making pretty pictures, but that's about it." Fortunately, these rather pessimistic attitudes are not reflective of my experience working with undergraduates. In fact, undergraduate research in mathematics is blossoming at a rapid rate. One need only peruse the titles and abstracts of the $A M S$ - $M A A$ SIAM Special Session on Research in Mathematics by Undergraduates from the recent Joint Mathematics Meetings to see the breadth and depth of undergraduate research. In recent years, the number and quality of student poster contributions to the Undergraduate Student Poster Session at the Joint Mathematics Meetings has also markedly increased. As further evidence, a new journal called Involve: A Journal of Mathematics has recently appeared to bridge the gap between strictly undergraduate journals and mainstream research journals. Manuscripts for Involve must qualify for publication in a research journal and they must include a minimum of at least one-third student authorship.

This article discusses some of the basics of conducting mathematical research with undergraduates. Topics covered include selecting good research students, finding appropriate research

*Dept. of Mathematics and Computer Science, College of the Holy Cross, 1 College St., Worcester, MA 01610. groberts@radius.holycross.edu (NSF Award No. DMS-0708741) 
problems, mentoring versus collaboration, presenting and publishing student work, and locating resources for supporting undergraduate research. I have been fortunate to mentor and collaborate with seven undergraduate researchers over the last eight years and have written four papers with undergraduate co-authors (two published, two submitted). Four of these talented students are now in doctoral programs in either mathematics or computer science. The perspective given here will be drawn from my experiences working at an undergraduate institution (College of the Holy Cross) although the topics discussed will hopefully apply to a more general audience.

By "undergraduate research," I mean investigations conducted by an undergraduate student on an original and challenging mathematics problem that may possibly lead to publication in a research journal. The undergraduates I have worked with are bright, curious, imaginative and ambitious. They can pursue tough problems and are not afraid of stretching their minds. In my experience, a motivated undergraduate researcher is not only capable of attacking a genuine research problem, but will often contribute in an unexpected and substantial manner to your own research program. The ultimate goal of conducting research with undergraduates is not to publish a paper but to enrich their educational experience and to develop their interest in scholarly work. Ideally, the experience will serve as a productive training ground for the world's future mathematicians and scientists.

\section{Selecting Good Research Students}

It is important to make a conscious and informed decision when selecting a research student. In many cases, due to the size of the pool or competition with other faculty, there may not be many options available. Don't expect a student to come to you. Even if your department has some type of required undergraduate senior project or thesis, being proactive and recruiting the right student can make all the difference.

One obvious source of potential candidates comes from those bright students in your own courses. If you are teaching a seminar in your area of expertise, try and recruit good sophomores

and juniors for your course so you will have a good crop of research candidates the following year. If you have exceptional first-year calculus students, keep an eye on them and discuss the possibility of doing research together further down the road. Many students are unaware of the plethora of opportunities for doing undergraduate research. Others lack the confidence to even consider such an endeavor. Having informative and supportive conversations early in their career is crucial. If your school has teams for contests such as the Putnam Exam or the Mathematical Contest in Modeling, this is an ideal place to recruit. You may have to be proactive within your department. Let your colleagues know you are interested in working with a student in field XYZ and ask them to send possible candidates your way.

It is worth mentioning that just because a student approaches you interested in conducting research, that does not imply you should immediately accept. Here are some questions to ponder when choosing a good research student:

- What is the student's academic background? What is their GPA in the major?

- Have they taken courses related to your research field and if so, how have they done? 
- If you haven't had them in class, what do other professors think of their abilities?

- Have they already had some research experience? eg. participation in an REU (Research Experience for Undergraduates) or other similar programs

- Are they good problem solvers? Are they inquisitive? Do they ask insightful questions in class?

- Have they demonstrated perseverance and determination in their coursework?

- Are they comfortable struggling with a hard problem?

- Do you get along well with this student? Are they mature?

- Do they have sufficient time during the academic year to commit to research?

- Are they interested in pursuing graduate study? What are their career goals?

A students' time and availability is an important consideration. Todays undergraduates have multiple extra-curricular demands on their time. Many hold jobs requiring several hours of weekly work in order to help pay for college expenses. Many are involved with clubs, athletics, musical groups, student government or important service work for the college. At Holy Cross (HC), a Division 1 school, athletic commitments are very substantial and it can be challenging, though certainly not impossible, to have a successful collaboration with a student athlete. It is important to inform a potential student of your expectations for their effort and time commitment during the course of your work together. For example, if the student is conducting a yearlong honors thesis or an independent study project, they should devote at least as much time as they would for any of their classes (eg. 10 hours per week). Ideally, they would have less academic pressures in their lives during the year of research. Collaborating with an undergrad who is a double major with a pre-med concentration, taking an extra course to graduate, is probably not the best option.

Another factor to consider when choosing a student is diversity, in particular race and gender. Part of trying to make mathematics more inclusive is to work with and encourage students from traditionally under-represented groups. This is particularly relevant if you have been conducting research with undergraduates for many years. Take stock of who you have been working with and determine whether you should be reaching out to other constituencies.

\section{$3 \quad$ Finding an Appropriate Problem}

Finding a good and appropriate research problem for your student is the key to having a successful experience. Joe Gallian, who has been running a highly successful REU program at the University of Minnesota Duluth for over thirty years, spends the entire year leading up to his summer program searching for good research problems [15]. In addition to browsing the literature and attending conferences, he also seeks out suggestions from colleagues and past participants. When each student arrives to Duluth, they find a recently written research paper with an accompanying 
problem waiting for them. Part of Gallian's success is matching the right problem with the right student.

It takes much effort and foresight to find the ideal topic for your student. It is important to remember that they are probably not aware of open problems in your field, nor do they have any idea what constitutes a true research problem. You will be the best judge of whether a problem is interesting, original and accessible to your student. It may also be the case that your student makes little progress or becomes disinterested in your chosen topic. Thus, it is prudent to have multiple problems in mind.

Sometimes a student will arrive to you with a particular subject of interest (eg. wavelets in medicine and biology or mathematics and climate change) that may not be in your field of specialty. This type of project may be more time consuming for you as advisor but also offers the opportunity for you to learn about a new branch of mathematics. It probably won't lead to original theorems or a research paper but it could be a stepping stone for work with future students or lead to a new seminar course in your department.

Another approach is to work with a student on advanced material common in the discipline (eg. measure theory or algebraic geometry) in order to prepare them for future study, perhaps in graduate school. This is an opportunity to fill some gaps in the upper-level offerings in your department and can be a rewarding and vital endeavor.

One of the most gratifying experiences is to incorporate your student into your own research program. While this is understandably easier in certain fields (eg. applied math or discrete math), it is becoming more common in the "pure" mathematics arena as well. Frank Morgan's great success with his geometry groups at Williams College is one such example (see his homepage for an impressive list of students and publications [12]). Not only is this a beneficial experience for your student, but it can also have a substantial impact on your own work. For example, I have been fortunate to find students capable of investigating some challenging problems in celestial mechanics. Lisa Melanson (HC, 2007) and I stumbled onto an interesting question in the planar, circular, restricted three-body problem (PCR3BP) that eventually led to a completely analytic proof of Saari's conjecture adapted to the PCR3BP [14]. It was Lisa who first expressed interest in the conjecture and later proved it for the case of equal masses using Gröbner bases. Although we didn't end up using her proof in the paper, her initial work was the catalyst for the overall result.

Conducting research with an undergraduate can also bring a needed respite from your usual academic responsibilities. If you have a relatively high teaching load, including many wellattended office hours during the week, then scheduling a regular weekly meeting with your student helps keep your research program active during a busy semester. I usually find my research meetings with students to be the highlight of my week. An added benefit is developing a type of collaboration that, due to the size or scope of your department, may be difficult to find locally. While working with an undergraduate is not going to be a replacement for collaboration with veterans in your field, it does provide much needed face-to-face contact and discussion, contradicting the discouragement and isolation often pervasive in our research environments.

There are several ways to involve an undergraduate in your research, and how you integrate your student should vary depending on their abilities. For example, some of my research students have had a substantial background in computer science. Thus, it was natural to have them writing programs as part of their work. This included generating intricate fractals and bifurcation 
diagrams with C++ as well as writing Matlab code to help with Newton polytope calculations. Often, the numerical and symbolic calculations on a computer lead to student-formed conjectures and eventually, theorems. Computer work also offers students an enjoyable and productive outlet from the usual frustrations of doing challenging mathematics. Generating something tangible such as a picture or a program keeps them feeling productive and positive.

Some of the best types of research problems for undergraduates involve a particular sub-case of a problem you are familiar with. For example, in the complicated Newtonian $n$-body problem, there are plenty of smaller, more accessible problems that can be attacked by a motivated undergraduate. These involve restricting the motion of some of the bodies [9] or searching for special solutions such as central configurations. Richard Guy's informative text Unsolved Problems in Number Theory offers future number theorists hundreds of open problems and conjectures [7]. According to the Mathematical Review of Alexander Hulpke, the paper Some computational experiments in number theory by Wieb Bosma [1] (investigating some problems from Guy's book) contains several experiments that are "easily accessible to undergraduate students with only an elementary number theory course as background and could be used as the basis of an undergraduate research project" [8]. Review and expository articles in publications such as the American Mathematical Monthly, The College Mathematics Journal or Mathematics Magazine may also present some options. Finally, many undergraduate textbooks now include suggestions for independent research projects. Two which come to mind (both used at Holy Cross) are Bob Devaney's A First Course in Chaotic Dynamical Systems [6] and the popular Ideals, Varieties, and Algorithms: An Introduction to Computational Algebraic Geometry and Commutative Algebra by Cox, Little and O'Shea [5].

It can also happen that a student will stumble onto an interesting problem by pushing ahead on a topic previously explored in class (eg. dynamical properties of the Ducci map [3] or a particular ODE model in math biology). An obvious benefit to this scenario is that, instead of having to sell your student on one of your own research problems, they arrive eager to begin work on a subject already of interest to them.

Regardless of the particular problem or topic you decide upon, students will always need to spend a substantial amount of time learning background material before they can make a meaningful contribution. This can be accomplished by providing appropriate texts or papers as well as assigning relevant homework problems or problems of your own design.

\section{Mentoring versus Collaboration}

One of the more perplexing issues I have encountered working with undergraduates is balancing my role between serving as a mentor to my students and treating them as full collaborators. This is particularly relevant when I have a student working with me on a research problem that I am very interested in solving. There have been moments where I follow one approach and my student tries another, and we meet the following week to share our findings. This, in effect, is a true research collaboration. Our mutual goal is to solve a problem and come up with an original result. It is a shared research experience not unlike the kind found when collaborating with a colleague.

The obvious difficulty that arises is the occurrence of an imbalance in the workload, when I 
find myself doing the bulk of the research for the sake of achieving the result. This is of little help to the students' development as a mathematician. It also runs counter to the goals of a bona fide undergraduate research experience wherein the student charts their own course with you serving as advisor. One way to avoid this pitfall lies with the appropriate choice of problem or set of tasks for your student. If your problem commands your interest to the extent that you want to devote all your free research time to it, then it's probably not going to serve as a good problem for your student. On the other hand, if there is a side-problem, a curiosity that you have never had time to explore but have always wondered about, then this could be an ideal investigation for your undergraduate researcher. I have also found that giving undergraduates specific tasks or roles in the research (eg. creating a useful program or generating important figures) is a great way to get them involved without stepping on their toes. It works especially well when the future progress of your joint work depends on their results.

One of the most important faculty roles in the undergraduate research process is that of supportive mentor. In terms of mathematics, students need regular guidance and supervision. They will have many questions that require your expertise, and, as mentioned above, you may have to take care not to solve their problems for them. Your job as mentor will require a fairly substantial amount of time and effort. During our summer research program at Holy Cross, I usually meet with my student(s) daily, often for several hours. This is particularly important at the start of the research experience. Students will also need advising if they are presenting their work at a conference or writing it up for publication.

However, of equal significance, is providing constant encouragement and enthusiastic support to your student. By demonstrating a clear and unyielding faith in their abilities, you can help them overcome the hurdles that inevitably arise. We all know that research can be a frustrating and emotionally demanding endeavor. Having done some as an undergraduate at Oberlin College under the guidance of Jim Walsh, I can recall some long, lonely nights in my library carrel staring at advanced texts in deep befuddlement. But Jim's confidence and appreciation of my efforts made it easier to push forward. It can mean everything to a student to let them know you are proud of their work. It is also important to listen to their concerns and acknowledge any feelings that come up around their work.

Another key issue worthy of mention is the importance of developing a close and communicative relationship with your student. The more solid your relationship, the better you will be able to mentor and/or collaborate. I recommend getting to know your research student outside of academia. One should obviously use some discretion here, but taking an interest in a students' life outside the classroom makes a big difference. It sends the message that you see them as a real person and that you are aware of their strengths and interests beyond mathematics. This point was repeatedly emphasized by several undergraduate participants on a panel at the Conference on Innovation in Undergraduate Teaching and Research at Montclair State University.

If you are giving a talk or attending a conference near your institution, try bringing your student along so they can make connections with other undergraduate researchers and feel part of a broader research community. Consider inviting your student over for dinner or meeting them at a school dining hall for lunch. This past summer I traveled by car for four to five hours with my current research student to the conference mentioned above at Montclair State. I also took him to a local baseball game. Things tend to go better when the research experience is as fun as possible. Joe Gallian's REU in Duluth requires students to participate in all-day field trips 
every Wednesday [15]. All of these types of extra-curricular activities help lay the foundation to develop an open and supportive mentoring relationship, which in many cases, will continue after the student graduates.

\section{$5 \quad$ Presenting and Publishing}

One critical component of undergraduate research is the student presentation. This provides a valuable opportunity for the student researcher to develop verbal communication skills and demonstrate mastery of a particular subject. It forces students to organize and summarize their findings, an excellent precursor to writing a paper. Student presentations at your home institution help foster a strong research climate and provide models for other students who may be interested in pursuing research.

Organizing an undergraduate research seminar or colloquium series is an excellent way to give students experience developing their speaking skills. In our department, each summer research student gives a brief presentation on their work at the end of the summer. Most also present a poster at a college-wide undergraduate summer research symposium in early September. These opportunities help prepare our students to participate in regional or national events such as the MAA sectional meetings, MathFest or the student poster session at the Joint Mathematics Meetings. There are also several specifically undergraduate conferences or symposia around the country such as the Hudson River Undergraduate Mathematics Conference and the Young Mathematicians Conference held at The Ohio State University each August. Another seemingly overlooked, yet enticing opportunity, is the Posters on the Hill event sponsored by the Conference on Undergraduate Research. This special event, open to students in mathematics and the sciences, takes place on Capitol Hill and affords undergraduate researchers the opportunity to showcase their work to members of congress.

Another important goal of undergraduate research is submitting results in the form of a publication. In my first meeting with a new research student, I highlight my intention for us to produce an original result that leads to a published paper in a refereed journal. This may seem a bit lofty or even naive, and it has not always been attained, but setting the bar high from the outset invigorates the entire research process. It can be a tremendously powerful motivation for the student as well as a boost for their confidence. My students enjoy knowing that their efforts could lead to a published result and the professional respect that commands. They benefit from being part of a larger project and appreciate being viewed as collaborators in that project. They also stand to gain valuable skills in technical writing and the publication process.

If the work of your student or your joint collaboration produces a result worthy of submission to a refereed research journal, then you should proudly submit it. However, if it is not at that level, there are still many good journals available that are specifically geared toward undergraduates. These include The College Mathematics Journal, Pi Mu Epsilon Journal, The Pentagon: The Official Journal of Kappa Mu Epsilon, Rose-Hulman Undergraduate Mathematics Journal, Furman University Electronic Journal of Undergraduate Mathematics, and Morehead Electronic Journal of Applicable Mathematics. There is also the appealing new journal Involve: A Journal of Mathematics that seeks to bridge the gap between research journals and those mentioned

above. The editorial board for Involve boasts many top-notch mathematicians who are dedi- 
cated to promoting undergraduate research. Any paper submitted to Involve must have at least one-third student authorship.

I should mention one caveat in regards to student authored or co-authored publications. Often, there is not enough time or resources for the student to finish the actual write-up of results. Indeed, in three of the four papers I have submitted with undergraduate co-authors, I have done most of the writing. This was partly due to the length of our collaboration but also a result of my haste in wanting to get the work submitted. Ideally, the research student will spend a summer and a semester doing the bulk of the heavy lifting, and another semester writing up the results and putting on the finishing touches. Unfortunately, research and publication rarely fit into such a nice and tidy schedule. Once students have graduated and moved onto new endeavors, it becomes increasingly difficult to continue collaboration and bring the project to a satisfactory conclusion. Thus it is prudent to set concrete deadlines during the project, including specific requirements for writing up results.

\section{Resources}

There are many sources of financial and professional support available for faculty conducting (or interested in developing) undergraduate research projects. The first place to look is your own institution. At $\mathrm{HC}$, we are very fortunate to have a 10 -week summer research program that supports approximately $60 \mathrm{HC}$ students in mathematics, the natural sciences and psychology. The program consists of student-faculty teams of researchers working on projects designed by the faculty mentor. In mathematics, a team usually consists of one or two students and one professor. Each student receives a summer stipend, funds to purchase research supplies, and room and board. There is also some money for travel support for students seeking to present their research at scientific meetings. However, faculty participating in the program do not receive a summer stipend. A weekly lunch seminar for all of the students is given by various faculty from the participating departments to discuss their recent work and to help create a cohesive research environment.

The HC summer research program has served as an ideal launch pad for my research students. All of the students I have worked with during the academic year began their research experience with me in the summer. This gave them enough time to learn the necessary background material and allowed us to delve deeper during the academic year. During the summer program, the distractions of the academic year are absent and a student's sole focus is on their research project. As described in the previous section, in order for my students to present and publish their research at an adequate level, they need to have several months (or an entire second semester of a yearlong project) available to accomplish their goals. It is very difficult to achieve this without the boost from the summer program.

If your institution does not have a summer program, or in your opinion, does not adequately support undergraduate research, consider approaching your administration to address this deficiency. The MAA report "Mathematics Research by Undergraduates: Costs and Benefits to Faculty and the Institution" makes a convincing argument in favor of undergraduate mathematics research and discusses some key distinctions between our undergraduate research activities and those found in other disciplines [11]. One excellent resource for both faculty and administrators 
is the Council on Undergraduate Research (CUR) whose mission is "to support and promote high-quality undergraduate student-faculty collaborative research and scholarship" [4]. CUR consists of individual faculty as well as colleges and universities as members (541 institutional members as of November, 2008). They provide numerous publications and outreach activities designed to help primarily undergraduate institutions establish or improve their undergraduate research programs. In addition to running the Posters on the Hill event mentioned previously, they also run a highly successful four-day proposal writing program designed to help participants secure funding from external agencies.

Another good resource for faculty is the Center for Undergraduate Research in Mathematics (CURM) at Brigham Young University (BYU) [2]. CURM runs an interesting program specifically geared towards supporting faculty mentors of undergraduate research projects in mathematics. Through the financial support of the National Science Foundation (NSF), CURM offers about 15 annual mini-grants ranging from $\$ 12,000$ to $\$ 20,000$ for faculty interested in conducting undergraduate research projects at their home institution with groups of 2-4 students. Part of this money is for faculty to "buy out" of a course in order to reduce their teaching load. The remainder goes to provide each research student with a $\$ 3,000$ stipend during the course of the year. The program includes a two-day training workshop for faculty taking place the summer before the research year commences, a mid-year meeting (during the Joint Mathematics Meetings) and a spring research conference at BYU (travel and lodging paid for by CURM).

Some of the information described above was brought to my attention via the recently established MAA Online Column of Resources for Undergraduate Research edited by Sarah Adams and Darren Narayan [10]. This looks to be a promising venue for faculty interested in learning and conversing about undergraduate mathematics research.

Lastly, there is a substantial amount of financial support available for faculty interested in involving undergraduates in their own research programs through the NSF Research in Undergraduate Institutions (RUI) grants [13]. The RUI program is specifically geared toward researchers at predominantly undergraduate institutions. Investigators apply for these grants through the specific NSF program in the disciplinary area of their research (eg. Division of Mathematical Sciences - Applied Math) but should indicate clearly (eg. in the title and project summary) that they are submitting an RUI proposal. In addition to the standard research proposal, applications must also include a brief "RUI Impact Statement" describing how the proposal will benefit the research and educational environment at your institution. Although competitive, the RUI program offers faculty seeking to conduct research with undergraduates excellent financial support.

\section{References}

[1] Bosma, W., Some computational experiments in number theory, Discovering mathematics with Magma, Algorithms Comput. Math. 19, Springer-Verlag, Berlin (2006), 1-30.

[2] Center for Mentoring Undergraduate Research in Mathematics, Brigham Young University, http://curm. byu.edu/ 
[3] Chamberland, M., Thomas, D. M., The N-number Ducci game, J. Difference Equ. Appl. 10, no. 3 (2004), 339-342.

[4] Council on Undergraduate Research, http://www.cur.org/

[5] Cox, D., Little, J., O'Shea D., Ideals, Varieties, and Algorithms: An Introduction to Computational Algebraic Geometry and Commutative Algebra, 3rd. ed., Springer, New York, 2007.

[6] Devaney, R. L., A First Course in Chaotic Dynamical Systems: Theory and Experiment, The Advanced Book Program, Westview Press, Perseus Books Publishing, L.L.C, 1992.

[7] Guy, R. K., Unsolved Problems in Number Theory, 3rd ed., Problem Books in Mathematics, Springer-Verlag, New York, 2004.

[8] Hulpke, A. J., Mathematical Reviews, MR2278921 (2007j:11177).

[9] Lodge, G., Walsh, J. A., Kramer, M., A trilinear three-body problem, Internat. J. Bifur. Chaos Appl. Sci. Engrg. 13, no. 8 (2003), 2141-2155.

[10] MAA Online Column of Resources for Undergraduate Research, Adams, S. and Narayan, D., editors, http://www.maa.org/columns/Resources/resources.html

[11] Mathematics Research by Undergraduates: Costs and Benefits to Faculty and the Institution, a report of the CUPM (Committee on the Undergraduate Program in Mathematics) subcommittee on Research by Undergraduates, Mathematical Association of America.

[12] Morgan, F., http://math.williams.edu/morgan/student-research-supervision/

[13] Research in Undergraduate Institutions (RUI), National Science Foundation (NSF), http://www.nsf.gov/funding/pgm_summ.jsp?pims_id=5518

[14] Roberts, G. E., Melanson, L., Saari's conjecture for the restricted three-body problem, Celestial Mech. Dyn. Astr. 97 (2007), 211-223.

[15] Robinson, S., In the Mix at Model REU: Creative Mentor, Talented Students, Hand-Matched Problems, SIAM News 37, no. 6, July 25, 2004. 